\title{
A Transformative Application-Oriented Activity in Action Learning: One Hug at a Time
}

\author{
James Curiel and Susan McEwen \\ American University in Cairo, Egypt
}

\begin{abstract}
This informal case study shares our experience with an Application-Oriented Activity, or AOA, herein called the "Letter Experiment." It highlights the strengths of Action Learning in generating reflection, enthusiasm, and team unity. Within the social science curriculum the Letter Experiment is especially useful in facilitating the teaching of microsociology and qualitative methodologies. In this activity students explore the effects of two common interpersonal gestures, letter writing and hugs, on a relationship with a significant elder. Students are asked to employ these gestures strategically and then to observe and record any changes in their relationships to the respective elders. The resulting changes can have a profound impact on student motivation, enhancing the value students place on their coursework.
\end{abstract}

\section{Introduction}

Action Learning is something of an enigma in higher education although it had its origins in academia decades ago, when Reginald Revans began work on his dissertation under J. J. Thomson. Considered something of a "renegade" at the time, Revans eventually found his way to the industrial recesses, where he and his methods were embraced from the 1940's onward.[1] Revans' strategy was to have small groups of managers from different coal mines and hospitals consult each other and work together on common problems, which ultimately led to significant improvements in production, working conditions, and worker morale.[2] Revans' method soon gained adherents among companies and corporations that welcomed the resulting profits. In the 1970's the work of Lennart Rohlins led to a parallel development in Sweden, further increasing Action Learning's scope and distribution. In the 1990's, the success of Action Learning in the business world was too significant for the academy to ignore, and the concept of Action Learning, informally banished a half century earlier, returned from whence it came.

For many academicians Action Learning may resemble the distant relative of whom they have heard but know little about. However, given its effectiveness as a teaching strategy, closer acquaintance is certainly merited. Our practice of AL ties it closely to the Experiential School, as articulated by Kolb and Kolb.[3] The object of this paper is to argue for the utility of Action Learning in the college classroom by illustrating how it may be done with an Application Oriented Activity (AOA) that we call the "Letter Experiment." As strong advocates of AL who have practiced it for more than eleven years in college-level Sociology courses, we have found this particular AOA effective in teaching social interaction, participant observation, and microsociology while promoting the AL goals of reflection and classroom unity. Moreover, it has demonstrated itself to be a transformative experience for students and teachers.

AL owes its existence to Revans' experience as Director of Education for the National Coal Board in Great Britain from 1945-1950. In this capacity, he observed that hands-on activities yielded greater comprehension of concepts than did lectures that focused on abstractions without reference to practical application.[4] Although AL can take many forms, it normally affords small groups of learners opportunities to work together on projects, building understanding from the experiences, reflection, group interactions, and questions that emerge from the process.[5] The rationale for AL is that people learn best when building on what they already know and from informal learning, where, it is believed, approximately eighty percent of learning takes place.[6] For example, Revans found that informal learning, reflection, and critical thinking took place in small group situations where members worked on real world problems that yielded real world results. In classic AL, Application Oriented Activities, AOA's, are exercises where small groups work on solving a problem that emerges from real need and which has practical applications.

In the business world the goal of a company is to sell a product or provide a service, which remains the primary task of the organization and is omnipresent. In the classroom, goals are more diverse and abstract. For example, within the Firestone Tire Company, where the company's survival depends on the successful production and sale of tires, the need to find solutions to real problems is more selfevident than in a social psychology class studying participant observation. For students the real-world problem to be solved may at odds with the goals of the teacher. Student problem-solving efforts may have less to do with learning than with practical issues like workload and grades. Meanwhile, the social psychology class deals in transmission of 
abstraction, a goal that may not be within the grasp of students' imagination. A further complication is that the abstractions to be transmitted change over the course of the semester. Unlike the work supervisor, the college teacher has more layers of decision to deal with in figuring out what will constitute a relevant and sufficiently engaging problem, how it applies to the abstraction to be taught, and how it will lend itself to the problemsolving efforts of groups whose agenda may be something other than acquisition of the corresponding abstraction. That is, the group needs to see the problem to be solved as more than a potentially meaningless classroom exercise. Strategically employed, AOAs can offer meaningful ways to connect classroom experience with abstractions that transcend the academic context.

At the University level, we have used AL in the form of AOAs, both in classrooms in the United States and in Egypt, to create informal learning environments where participants are prompted to access prior experiential knowledge and bring it to bear on new classroom experiences. The Letter Experiment is an AOA used to explore abstractions inherent in micro-sociology, face-to-face interaction, and qualitative methodologies, such as participant observation and thick description. In the Letter Experiment, students experience dual roles. They are both agents initiating change via simple gestures in a relationship and observers who record any resulting changes in that relationship. Thus, the experiment emphasizes the agency of students on more than one axis.

\section{The Letter Experiment}

The Letter Experiment tests principles established by Harlow's studies affirming the critical nature of touch as well as by the legal precedent that gives priority to hand written evidence. It begins with students in the context of their extended families. They are first asked to hand write a letter to an elder. It is fundamental to the experiment that the letter not be typed or mediated by a machine, that it be hand written. Central to the experiment is the reduction of mediation, strengthening face-to-face interaction as much as possible. The premise behind this is that small gestures in direct face-to-face interaction have larger impacts than do mediated gestures. Once the letter has been written, students then mail it to an elder, such as a grandparent or great-aunt or uncle. An " “elder" is here defined more specifically as a person viewed by the student and/or family as someone older and wiser, a trusted advisor.

Once the letter has been received and read, students then visit the elder. Students may wonder how they will know that the letter has been read. In our experience, this does not pose a problem. Students usually find out almost immediately because the elder will either call the student or contact another relative, who will then inform the student. In the absence of this information, the student may call the elder to inquire about the letter. During the subsequent visit the student is to give the elder a hug at a time when the elder would normally not expect one; in other words, the hug is to be experienced as spontaneous.

Afterwards, students write down the details of their experiment: when the letter was written; briefly, without personal information, what the contents were; how they learned it had been read; when the visit occurred; the context of the unexpected hug; and finally, what changes, if any, took place after the experiment. They are also asked to describe whether the Letter Experiment changed their relationship with the elder and if so, to try to account for the change. As Ranson and Martin have noted, in Action Learning the process of learning "why" something is accomplished is more important than what has been accomplished. The "what" leads to rudimentary definition, while the "why" is relational and entails deeper understanding of an entity's connection to its environment.[7]

In the United States the Letter Experiment afforded an opportunity for our students to contact relatives in a society where jobs tend to be prioritized over family bonds, a situation classically analyzed by sociologists to have atomistic effects on familial relations.[8] Our American students described dramatic changes in the relationships with their elders. In Egypt, however, familial ties are stronger, and it is common for extended families to live in the same neighborhoods, even buildings, and to share a weekly meal together. Thus, with our Egyptian students we expected any effects on students' relationships to be more subtle than had been the case in the United States. In fact, though, the activity in Egypt had an equally significant impact as in the United States, and it was equally effective in stimulating enthusiasm and reflection.

\section{Results}

Our anecdotal evidence in support of this activity comes from six classes at the American University in Cairo, Egypt, during the spring and fall semesters of 2011, and is supplemented by averages drawn from these classes, each with an average of enrollment of 24.8 students. Our first observation involved the high degree of enthusiasm demonstrated for the assignment and increased class participation, which we assessed based on several students' unusually early, pre-deadline submissions of their initial write-ups as well as by a higher than average rate of attendance on the day the assignment was due. For example, in the fall 2011 classes, the prior session absences numbered 13 while absences on the due date numbered four, a substantial reduction by 
almost $70 \%$. In each class, at least one student emailed the written assignment as soon as the experiment was completed. As one student noted, "I'm actually glad I got to do such an assignment because not only did I enjoy it, but I also feel like I got to say a lot to my grandma that I normally wouldn't under usual circumstances." Another student, who submitted a hard copy well ahead of the due date, commented, "This assignment clearly proves that simple genuine words and gestures can indeed change your relationship with another individual." On the assignment due date, a significant number of students arrived early in order to express their gratitude for the way that the assignment had improved the relationship to their elder. This sentiment was evidenced in statements like, "I regret that I didn't do that a long time ago; I wish I took this course in [high] school or even earlier than that." In addition to observing higher than normal attendance on the due date, we experienced what was by far the richest classroom discussion of the semester. The dramatic interpersonal results prompted students to actively process their experiences and to reflect on what had taken place and why.

The students were impressed with the degree of change effected in these outside-of-class relationships, and many reported that after the unexpected hug, both the elder and the student became tearful and held each other more closely: "I could feel her hugging me tighter than usual instead of the [usual] cheek kiss and soft embrace.” Another observed that this hug, where both began crying, made him feel "safe." One student reported that her grandmother cried and told her she had dreamed of receiving such a letter but that "no one writes," as well as that her grandmother was keeping the letter in her wallet so it could always be with her.

Others reported consequences were the elder's making gifts to the student, insisting on sitting near the student for the rest of day and at the weekly meal, engaging in lengthy conversations with the student, and initiating daily phone contact with the student to check in. At least one elder per class saved the letter in a special box. In several instances at the weekly meals, the elder took the student aside and noted how special he or she was, causing the student to cry. One student awoke to find that his grandmother had come over to cook breakfast in bed for him, and she insisted on preparing his favorite foods for several days. This instance of the elder cooking the student's favorite food averaged at least one per class. Students were surprised to see the profound effects of such simple interpersonal gestures: "The rest of the evening Grandmother sits next to me gently stroking my hair."

In attempting the assignment, many students realized they had never written a letter before and observed that the act of writing promoted thought, noting that while writing they found themselves reevaluating the relationship with the elder: "During writing, I discovered a lot of favors she did for me which I was taking for granted." The number of grandparents who were saving the letter in its own box, in their wallet, or in other "special" places points to the increasing rarity of handwritten letters as well as the value in receiving communication in the "old way." For many of the students this old way was a new way of communication, and for the first time they understood its power.

The Letter Experiment revealed to the American instructors the degree of inter-generational formality in Egyptian family relationships. In fact, the greatest overall insight concerning the unexpected Egyptian results was that the increase in closeness created a context of decreased social distance in what had been a formal relationship with more highly ritualized modes of interaction. As one student reflected, before the Letter Experiment she had had a "Grandfather," a "stranger" to whom she said a formal obligatory hello and goodbye at weekly meals and family gatherings; however, after the experiment her grandfather became "a friend I could talk to." More than anything, the letter and the hug opened the relationship between the student and elder to one of increased communication. On average at least two students per class scheduled special visits with their elder, which involved extended conversations of 2-5 hours. These involved sharing details of their lives and stories about the student's and elder's parents. Such stories gave the elder and student more information about each other as well as about members of the extended family. Students reported that these conversations helped them feel more connected to the elder and the rest of the family. One student summed it up by saying, "This assignment really broke the boundaries between us and made us have a really close relationship."

\section{Transformation and Benefits}

Practitioners of AL call such AOAs "transformative" because they help students see their social world in a new light but perhaps more significantly, enhance their view of what education can offer. As Ranson and Martin have observed, "The central challenge of our time...is to transform the way people think of themselves and what they are capable of. It is only by changing the sense students have of themselves as learners that they can begin to develop their capacities and realize their potential."[9] Here the students' practical goals become more aligned with the teacher's, as they encounter evidence that the acquisition of knowledge may be a means to make significant, tangible changes in their lives. The experiment helps students to see themselves and their elders in a new light, thus transforming their self-image and as well as their 
relationships to others. First, reflection begins with the letter, a new act for many, which requires them to develop a rationale for expressing appreciation to the elder by thinking of the kindnesses an elder has shown to them. For many, the act of remembering what to be thankful for for is new in that they have not previously considered in a more holistic way the benefits the relationship has afforded them. In evaluating the relationship, students become aware of deeper feelings of gratitude than are available in more formulaic expressions of thanks. This provides motivation for writing the initial letter. The elder's tears, joy, and other expressions of pleasure are both profoundly gratifying to the students and provide an unexpected feeling of empowerment as they discover their own capacity to make a difference in the life of another. Hence, we find an almost universal claim of surprise that "I could make my grandparent so happy with such a simple act."

The student is no longer a passive recipient of the largesse of elders, but is an initiator with the power to "make" someone happy on their own initiative and motivated by good feeling, not merely because of a pleasing appearance, money in the bank, a desirable automobile, or other superficial attributes. The experiment has empowered them and changed their sense of what they can do, and it has provided a new experience of their capacities as human beings. We speculate that is this realization and accompanying sense of accomplishment that result in the enthusiasm evidenced by the proactive early submission of assignments and increased class attendance and participation. Students want to share their positive results with the instructor and classmates.

The Letter Experiment can be transformative for the whole class as it builds team unity through a shared experience. Students develop a shared memory as they discover similar experiences with the task. This can lead to further conversation and new friendships in the context of stronger relationships and a sense of agency and reciprocation. The shared experience provides a level of intimacy around an insight that only members of the class understand. The experiment builds not only a stronger relationship between the student and the elder, but also a stronger camaraderie among students and between students and instructor.

The experience leads to a more effective classroom community. This begins on the due date of results, when students are not only early for class, but they are eager to share their results and to listen to others. It takes less time for the class to quiet down and for students to listen actively to each other. The instructor devotes less time and energy eliciting attention and turning the focus away from cell phones and other distractions, something that the increased intimacy of the initial experience supports in later meetings. The shared knowledge results in a new appreciation of the potential of the classroom, one's classmates, and of the teacher's role in creating meaningful conditions for learning. Students' open expressions of appreciation provide validation for the teacher, and such interactions encourage behaviors that strengthen relationships and empower both teacher and learner. As Ranson and Martin have noted, "The unfolding agency of the self always grows out of the interaction with others.”[10]

Ultimately, the Letter Experiment provides avenues for students to develop personal agency through interactions with their relatives, classmates, and instructor. For the teacher these tools can be transformative as well. Beyond providing a gratifying classroom experience, they affirm the potential of social science education to provide meaningful classroom encounters that can model the potential for broader social change.

\section{References}

[1] Judy O’Neil and Victoria J. Marsick, Understanding Action Learning, New York: American Management Association, 2007, pp.3-4.

[2] Judy O’Neil and Victoria J. Marsick, Understanding Action Learning, New York: American Management Association, 2007, p.4.

[3] Judy O'Neil and Victoria J. Marsick, Understanding Action Learning, New York: American Management Association, 2007, pp.7-9; Alicia Kolb and David A. Kolb, "Learning Styles and Learning Spaces: Enhancing Experiential Learning in Higher Education”, Academy of Management Learning \& Education, Vol.4, No.2, 2005, p.194.

[4] Reginald Revans, The Origins and Growth of Action Learning, Malabar, Florida: Krieger Publishing Company, 1982.

[5] Judy O’Neil and Victoria J. Marsick, Understanding Action Learning, New York: American Management Association, 2007, pp.xii-xiii.

[6] Judy O'Neil and Victoria J. Marsick, Understanding Action Learning, New York: American Management Association, 2007, pp.vii-viii.

[7] Stewart Ranson and Jane Martin, "A Theory of Learning”, British Journal of Educational Studies, Vol.44, No.1, March 1996, p.12.

[8] Emile Durkheim, Suicide, New York: The Free Press, 1951; David Reisman, The Lonely Crowd, New Haven, Connecticut: Yale University Press, 1950.

[9] Stewart Ranson and Jane Martin, "A Theory of Learning”, British Journal of Educational Studies, Vol.44, No.1, March 1996, p.11.

[10] Stewart Ranson and Jane Martin, “A Theory of Learning”, British Journal of Educational Studies, Vol.44, No.1, March 1996, p.14. 